\title{
GAP-43 gene expression regulates information storage
}

\author{
Matthew R. Holahan, ${ }^{1,2}$ Kyle S. Honegger, Nino Tabatadze, and Aryeh Routtenberg ${ }^{2}$ \\ Departments of Psychology and Neurobiology and Physiology in the Northwestern University Interdepartmental Neuroscience \\ (NUIN) Program, Northwestern University, Evanston, Illinois 60208, USA
}

\begin{abstract}
Previous reports have shown that overexpression of the growth- and plasticity-associated protein GAP-43 improves memory. However, the relation between the levels of this protein to memory enhancement remains unknown. Here, we studied this issue in transgenic mice (G-Phos) overexpressing native, chick GAP-43. These G-Phos mice could be divided at the behavioral level into "spatial bright" and "spatial dull" groups based on their performance on two hidden platform water maze tasks. G-Phos dull mice showed both acquisition and retention deficits on the fixed hidden platform task, but were able to learn a visible platform task. G-Phos bright mice showed memory enhancement relative to wild type on the more difficult movable hidden platform spatial memory task. In the hippocampus, the G-Phos dull group showed a 50\% greater transgenic GAP-43 protein level and a twofold elevated transgenic GAP-43 mRNA level than that measured in the G-Phos bright group. Unexpectedly, the dull group also showed an $80 \%$ reduction in hippocampal Taul staining. The high levels of GAP-43 seen here leading to memory impairment find its histochemical and behavioral parallel in the observation of Rekart et al. (Neuroscience 126: 579-584) who described elevated levels of GAP-43 protein in the hippocampus of Alzheimer's patients. The present data suggest that moderate overexpression of a phosphorylatable plasticity-related protein can enhance memory, while excessive overexpression may produce a "neuroplasticity burden" leading to degenerative and hypertrophic events culminating in memory dysfunction.
\end{abstract}

The growth- and plasticity-associated protein, GAP-43, plays a central role in the learning and memory process. GAP-43 is neuron-specific (Chan et al. 1986; Basi et al. 1987; Alexander et al. 1988; Liu and Storm 1989; Skene and Virag 1989; Zuber et al. 1989; Nielander et al. 1990), is found in high concentrations in growth cones (Nelson et al. 1989), and is closely associated with regenerative and developmental growth (Skene 1989; Strittmatter et al. 1995). Its activity is regulated by a protein kinase C (PKC) phosphorylation site (Alexander et al. 1988; De Graan et al. 1990a) embedded within a calmodulin-binding domain (Alexander et al. 1988) that exist in a yin-yang relation. GAP-43 demonstrates a direct relation between its phosphorylation state and enhancement of LTP (Lovinger et al. 1985, 1986; Lovinger and Routtenberg 1988; Gianotti et al. 1992) as well as behavioral learning (Routtenberg and Ehrlich 1975; Ehrlich et al. 1977; Cammarota et al. 1997; Young et al. 2000, 2002), suggesting a pivotal role for this presynaptic protein in mnemonic function (for reviews, see Benowitz and Routtenberg 1987, 1997; Perrone Bizzozero and Tanner 2006).

Transgenic overexpression of the phosphorylatable (GPhos), but not the nonphosphorylatable (G-NonP) or permanently (pseudo)phosphorylated (G-Perm), form of GAP-43 in mice enhanced memory on a radial arm maze task (Routtenberg et al. 2000). This selective enhancement demonstrated that the PKC phosphorylation site on GAP-43, rather than simply the elevation of GAP-43 protein levels, is a critical determinant of enhanced memory-related performance. It also provided for the first time a direct causal link between elevated levels of phosphorylatable GAP-43 and memory function.

'Present address: Department of Psychology, Carleton University, B550 Loeb Building, 1125 Colonel By Dr., Ottawa, Ontario, Canada K1S 5B6.

${ }^{2}$ Corresponding authors.

E-mail matthew holahan@carleton.ca; fax (613) 520-3667.

E-mail aryeh@northwestern.edu; fax (847) 491-3557.

Article is online at http://www.learnmem.org/cgi/doi/10.1101/lm.581907.
In addition to its role in facilitating plasticity-related phenomena, a significant and selective elevation in GAP-43 protein labeling in a subfield of the hippocampus (CA1-SLM) in Alzheimer's disease patients compared with age-matched controls has been reported (Rekart et al. 2004). This study described a positive correlation between Braak stage and GAP-43 protein labeling, suggesting the possibility that excessive levels of GAP- 43 could be related to memory dysfunction, though whether GAP-43 upregulation was a cause or effect remains moot.

Because of the preponderance of current memory studies using the water maze, we initiated a series of studies on the role of GAP-43 protein levels in regulating memory function in this behavioral situation, which would also provide a test of the learning task generality of the Routtenberg et al. (2000) findings.

\section{Results}

Hidden platform: Fixed location

In a total of nine G-Phos transgenic mice from three different litters, we observed a bimodal distribution in their ability to acquire the fixed hidden platform task (Fig. 1A). By the third training day, four G-Phos mice showed a $40 \%$ reduction in their latencies, an indication of learning, to locate the hidden platform (Fig. 1A, solid lines) while the others ( $\mathrm{n}=5$, dashed lines) showed no reduction in their latencies from the first trial, indicating no learning had occurred. We termed the former "bright" and the latter "dull" in homage to the early days of work on selective breeding and maze performance (Tryon 1940). On the third training day, the dull mice scored only $7.5 \%$ correct trials (i.e., finding the platform in the allotted time) out of the eight trials per animal. This was in comparison to the G-Phos bright mice that achieved $81.25 \%$ correct trials. Of the dull mice, three continued to show deficits up to Day 5, while the other two showed slight improvements.

Analysis of the group means over the five training days were 

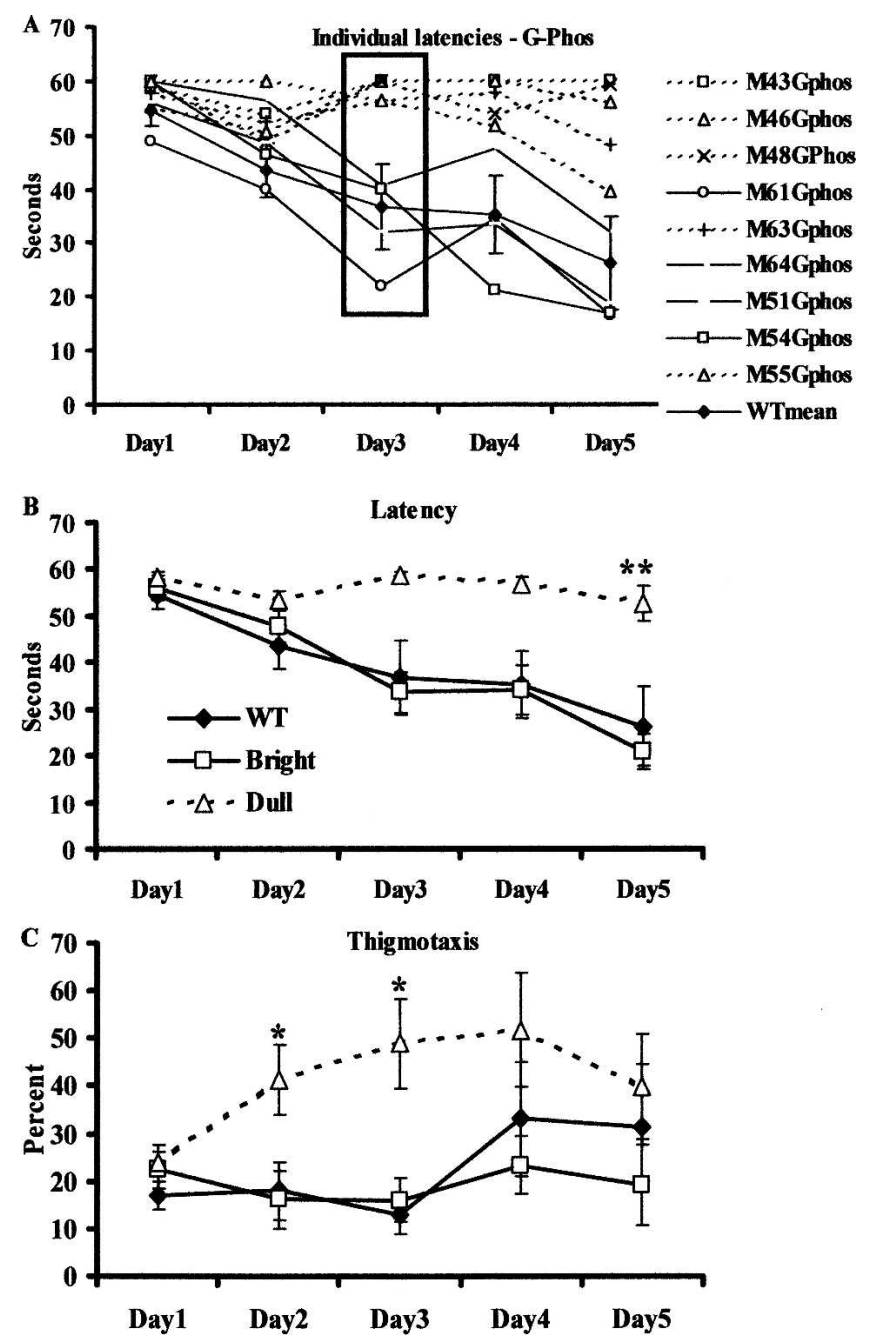

Figure 1. G-Phos transgenic mice formed two subgroups based on latencies to locate a hidden platform. (A) Individual acquisition data for the hidden platform water maze task measured as latency to locate the platform (in seconds) in the G-Phos transgenic mice. By Day 3, the transgenic mice could be clearly divided into two groups: G-Phos bright (solid black lines, open symbols) were those that showed reductions in their latencies to locate the platform similar to the wild type mean (WT, black line), and G-Phos dull (dashed lines, open symbols) were those that did not show reductions in their latencies by Day 3-most showed little or no improvement in performance by Day 5. (B) Mean acquisition data for the hidden platform water maze task measured as latency to locate the platform (in seconds). The G-Phos dull mice showed longer latencies on Day 5 compared with the other two groups $(* * P<0.01)$. (C) Percent path length spent swimming in the perimeter of the pool near the wall (thigmotaxis). The G-Phos dull mice showed more thigmotaxis on Days 2 and $3\left({ }^{*} P<0.05\right)$ but seemed to recover by Day 5 .

calculated for the wild-type group and the G-Phos group divided into the maze bright and maze dull groups. A two-way ANOVA (group by day) applied to the acquisition latencies (Fig. 1B) revealed a significant interaction $\left(F_{(8,44)}=3.48, P<0.01\right)$, indicating that the dull mice showed persistent elevated latencies compared with both the bright and wild-type groups after the five training days (Fisher's least significant difference post-hoc test [LSD], $P<0.01$ ), while the G-Phos bright and wild-type groups did not differ.

Analysis of where the groups spent their time swimming during training revealed that the G-Phos dull group spent significantly more time swimming near the perimeter of the pool than both other groups (thigmotaxis, Fig. 1C; two-way ANOVA, Day $F_{(4,8)}=4.05, P<0.01$, Group $F_{(2,11)}=2.68, P=0.11$, Interaction $\left.F_{(8,44)}=2.45, P<0.05\right)$. This was particularly evident on Days 2 and 3 of training. It is interesting to note that the percent of thigmotaxis in the G-Phos dull group tended to increase over the days, peaking on Days 3 and 4 then decreasing by Day 5 .

When the platform was removed and the animals were given a probe test $7 \mathrm{~d}$ after the last training day (Fig. 2), the G-Phos dulls did not spend more time searching in the annulus associated with the platform compared with the other two groups (planned pairwise comparisons on the percent time in target annulus: wild type vs. G-Phos dulls $F_{(1,8)}=9.69, P<0.01$ and G-Phos brights vs. G-Phos dulls $F_{(1,7)}=16.13, P<0.01$; Fig. 2A). Occupancy plots (Fig. 2B) showed that the G-Phos dulls tended to show a diffuse search pattern in all quadrants with some tendency to spend more time in the quadrant opposite the target, while the G-Phos brights showed a directed search of the area where the platform was located during training, which was similar to the wild type occupancy plot.

Results from the first trial of the fifth training day during acquisition indicated that the G-Phos dull group showed memory impairments in the shorter-term (i.e., 24-h retention interval). The mean latency to reach the platform on the first trial of Day 5 for the G-Phos dull group was $50.7 \pm 8.7 \mathrm{sec}$ (mean \pm SEM) while the latency for the G-Phos bright group was $26.8 \pm 12.8 \mathrm{sec}$ and $19.2 \pm 4.2$ for the wild-type group. This suggests that after a 24-h interval, the G-Phos dull group continue to show impaired memory.

\section{Visible platform}

A separate group of mice ( $n=6$ G-Phos and $n=3$ wild-type littermates) were trained and tested on the hidden platform water maze task, and again we observed a bimodal distribution in learn-
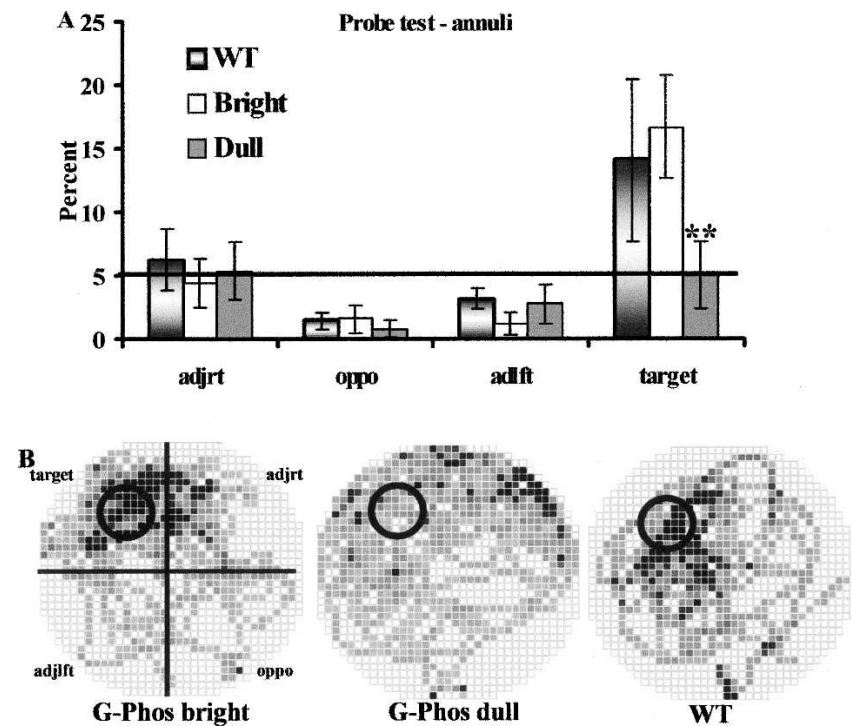

Figure 2. After $5 \mathrm{~d}$ of training on the hidden platform water maze task and a 7-d interval with no training, all mice were given a free swim in the pool with the platform removed (probe retention test). During this test, G-Phos dull mice $(n=5)$ did not search selectively in the target area (annulus) where the platform had been located during training. $(A)$ The percent time spent searching in each of the four annuli during the $60-\mathrm{sec}$ test; $(B)$ the occupancy plots. Both wild type (WT, $\mathrm{n}=5$ ) and G-Phos bright $(n=4)$ spent significantly more time searching in the target annulus than G-Phos dull. ( ${ }^{* *} P<0.01$ ). (Black squares) Regions of highest occupancy; (white squares) regions of no occupancy. These data indicate a memory deficit in the G-Phos dull group. 
ing ability in the G-Phos mice ( $\mathrm{n}=3$ G-Phos dulls and $\mathrm{n}=3$ G-Phos brights; Fig. 3A, see inset). This is important to note as it demonstrates a second replication of the initial finding that a subgroup of G-Phos transgenic mice show impaired spatial learning as carried out by a third experimenter ( $\mathrm{H}$. Thakur).

Ten days after hidden platform training, the mice were trained on a visible platform water maze task. Figure 3A shows that all groups (wild type, brights, and dulls) demonstrated similar acquisition curves on both days of visible platform training (group by trial two-way ANOVA, Trial $F_{(9,18)}=3.76, P<0.01$; Group $\left.F_{(2,6)}<1.0\right)$. These data indicate that the G-Phos dulls can successfully navigate to and mount the visible platform similarly to the G-Phos bright and wild-type groups and that their spatial deficit is unlikely to be explained by performance factors.

\section{Hidden platform: Nonmatching-to-place task}

In a previous report (Routtenberg et al. 2000), both wild-type and G-Phos transgenic mice acquired the standard radial arm maze at similar levels. However, when the task was more challenging, G-Phos mice showed superior mnemonic ability compared with wild-type mice (Routtenberg et al. 2000). Presently, we sought to determine if the G-Phos transgenic mice that learned the fixed
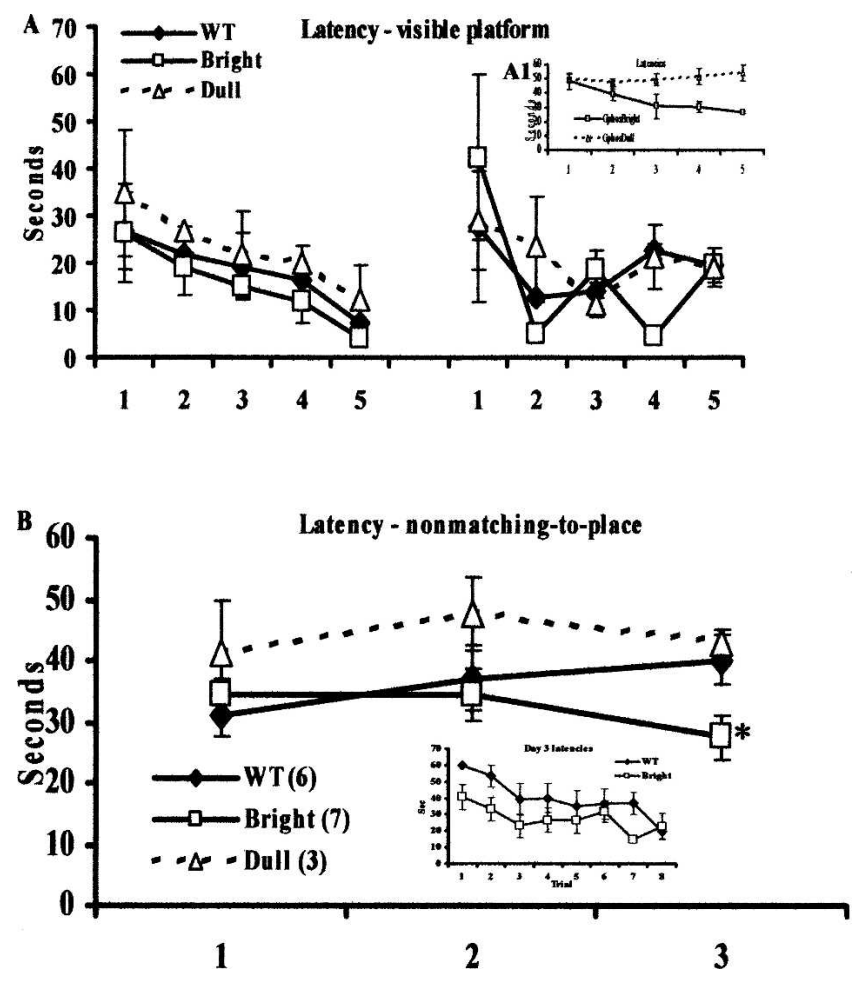

Figure 3. G-Phos dull mice can learn the visible platform task, and G-Phos bright mice show memory enhancement on more difficult water maze tasks. (A) All groups (WT, $\mathrm{n}=3$; G-Phos brights, $\mathrm{n}=3$; G-Phos dulls, $\mathrm{n}=3$ ) showed similar acquisition curves on both days of visible platform training even when training on the hidden platform revealed deficits $(A 1$, inset) in half of the G-Phos mice $(\mathrm{n}=3)$. (B) Mice (WT, $\mathrm{n}=6$; G-Phos bright, $\mathrm{n}=7$; and $\mathrm{G}$-Phos dull, $\mathrm{n}=3$ prescreened on a fixed hidden platform task, data not shown) were trained on a nonmatching-to-place task, where on each day the hidden platform was located in a different quadrant. By Day 3, the G-Phos bright group showed reduced latencies to locate the platform in the new quadrant compared with wild-type littermate controls $\left({ }^{*} P<0.05\right)$, suggesting memory enhancement in the GPhos bright group. (Inset) A trial-by-trial analysis of the Day 3 latencies. These data revealed that the G-Phos bright group showed lower latencies than the wild-type group during the first four training trials. hidden platform water maze task similarly to wild type would show memory enhancement if the task demands were increased.

\section{Pedigree of G-Phos mice}

We screened two additional, separate litters of G-Phos transgenic mice and their wild-type littermates on the hidden platform task and found a total of seven G-Phos mice that learned the fixed hidden platform task similarly to wild-type mice $(n=6)$ and three that did not. Interestingly, analysis of the offspring from two G-Phos parents (transgenic male and transgenic female) showed a 50:50 ratio of G-Phos brights and G-Phos dulls $(n=3$ / group), indicating the possibility that one parent was heterozygous and the other homozygous. However, when the female was wild type and the male was G-Phos transgenic, no G-Phos dulls were present. Rather, there was an approximate 50:50 ratio of G-Phos brights to wild type ( $\mathrm{n}=4$ G-Phos bright, $\mathrm{n}=6$ wild type), indicating that the G-Phos male was hemizygous. We then tested all of these mice (G-Phos dulls and brights and wild type) on a nonmatching-to-place task where the hidden platform was located in a new position each day of training.

\section{Performance on the movable hidden platform}

On the first and second days when the hidden platform was located in a different quadrant, both wild type and G-Phos brights showed similar latencies to locate the platform (Fig. 3B). By Day 3, the G-Phos brights showed significantly lower latencies to locate the platform in this new quadrant than the wild-type group (two-way ANOVA, day by group, interaction $F_{(2,22)}=3.46$, $P<0.05$, LSD post-hoc test on Day $3, P<0.05$ G-Phos brights vs. wild type; Fig. 3B; note that the G-Phos dull group was NOT included in the statistical analysis due to the low number of mice; the data are presented on Fig. 3B for comparison). A trialby-trial analysis of the Day 3 performance between the G-Phos bright and wild-type groups (Fig. 3B, inset) revealed that the GPhos bright group showed lower latencies on the first four trials of training than the wild-type group. Both groups showed similar performance during the last four trials. These data show that the G-Phos subgroup of mice that can learn the fixed hidden platform task also show memory enhancement on more difficult spatial tasks.

\section{GAP-43 and ZnT3 immunohistochemistry}

Because prior evidence with G-Phos mice had shown elevated GAP-43 mRNA expression in the granule cells of the hippocampus (Routtenberg et al. 2000), we examined immunohistochemical stains both for GAP-43 (both endogenous and transgenic) and the zinc transporter (ZnT3; Wenzel et al. 1997) in mossy fibers as well as other hippocampal subfields. Staining in the wild-type mouse (Fig. 4A) revealed a pattern of endogenous GAP-43 protein that was easily discerned in the stratum lacunosum moleculare (SLM) of the CA1 hippocampal subfield and the inner molecular layer (IML) of the granule cells. The ZnT3 labeling was highly concentrated in the CA3 stratum lucidum (mossy fiber terminal field [MFTF] zone), with lower levels of staining in the CA1 SLM and stratum radiatum (SR). In the wild-type mouse, ZnT3 labeled the suprapyramidal mossy fiber field (SP-MF) that terminates exclusively in the SL on apical dendrites of CA3 pyramidal cells and the infra/intrapyramidal mossy fiber field (IIP-MF) that appears mainly restricted to the most proximal aspects of the CA3 stratum oriens (S.O.) on the basal dendrites (Fig. 4A).

Both G-Phos subtypes (brights and dulls; Fig. 4B,C) showed high levels of GAP-43 staining in the CA3 SL compared with the wild-type group. In the G-Phos dull mice, there appeared to be higher levels of GAP-43 protein staining compared with both the G-Phos brights and wild-type mice. Qualitatively, the G-Phos 


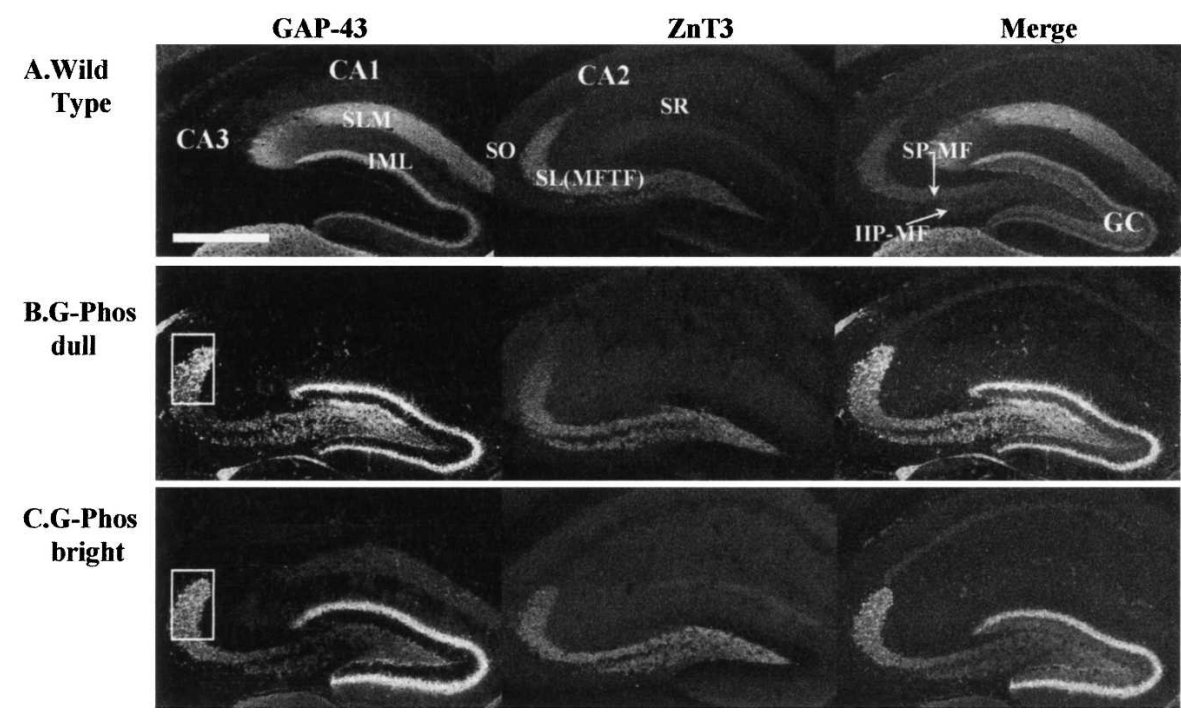

Figure 4. Immunohistochemical localization of the endogenous (mouse) and transgenic (chicken) GAP-43 protein, the ZnT3 protein, and their merged image in wild-type mice $(A)$, the G-Phos dull mice $(B)$, and the G-Phos bright mice (C). Staining in the wild-type mouse revealed no traces of GAP-43 staining in the mossy fiber pathways as labeled with the ZnT3 antibody. There was a striking pattern of elevated GAP-43 staining in the CA3 SL region of both G-Phos subgroups, which appeared to overlap with the ZnT3 staining. This points to an increased level of GAP-43 in the G-Phos groups located in the mossy fiber axonal terminals. (SLM) stratum lacunosome moleculare, (IML) inner molecular layer of the granule cells (GC), (SR) stratum radiatum, [SL(MFTF)] stratum lucidum (mossy fiber terminal field), (SO) stratum oriens, (SP-MF) supra-pyramidal mossy fiber pathway, (IIP-MF) infra/intrapyramidal mossy fiber pathway. Scale bar in $A, 500 \mu \mathrm{m}$.

dull group showed brighter GAP-43 protein staining in the IML of the granule cells, the hilus of the dentate gyrus, and the dorsal tip of the MFTF in SL (boxed-in area, Fig. 4B,C). In contrast, the G-Phos bright mice showed a more even distribution of GAP-43 in the SL (cf. Fig. 4, B and C).

\section{In situ hybridization of transgenic GAP-43 mRNA}

To determine if the elevated level of GAP-43 protein in G-Phos dull mice was a result of elevated mRNA expression, we carried out in situ hybridization for transgenic GAP-43 mRNA (Fig. 5). Transgene GAP-43 mRNA signals in the wild-type mouse (Fig. 5A) were at background levels, indicating that our probe did not recognize endogenous GAP-43 mRNA. There was a dramatic difference between the G-Phos subgroups (brights and dulls) in transgenic GAP-43 mRNA expression. G-Phos dulls $(\mathrm{n}=5)$ consistently and reliably showed higher levels of transgene mRNA expression in all areas examined (hippocampus, thalamus, amygdala, and cortex; cf. Fig. 5, B and C) than G-Phos brights $(n=4)$. Relative optical density measurements of transgene mRNA signal in granule cells (Fig. 5D) revealed an almost 2.5 -fold elevation in G-Phos dulls over G-Phos brights ( $t$-test; $P<0.01$ ). This, in combination with the elevated protein levels, suggested that the higher levels of transgenic protein in the G-Phos dull group was a likely contributing factor that lead to poor spatial information processing.

\section{Endogenous GAP-43 protein analysis}

In a separate group of G-Phos transgenic mice $(n=10)$ that were trained on the hidden platform version of the water maze task, we analyzed the amount of endogenous GAP-43 protein using Western blot quantification. By the third day of training, mice could be divided into bright $(n=4)$ and dull $(n=6)$ subgroups. The mean latency to locate the platform on the third day of training in these groups was $28.6 \pm 3.3 \mathrm{sec}$ (mean \pm SEM; GPhos bright) and $52.9 \pm 1.2 \mathrm{sec}(\mathrm{G}$-Phos dull $)(P<0.0001$; Fig.
6A1). Analysis of the endogenous GAP43 protein levels in the hippocampus revealed no significant differences between the bright and dull G-Phos classification (Fig. 6A2). These data indicate that in the G-Phos dull mice, endogenous GAP-43 protein levels are not reduced compared with the G-Phos bright mice. This adds further weight to the proposed role of elevated transgenic protein underlying the observed impairments in memory function.

\section{Microtubule-associated protein immunohistochemistry}

Would the elevated levels of GAP-43 in G-Phos dull animals have consequences for expression of other closely related axonal proteins that might shed light on their poor spatial performance? To approach this question we studied the distribution of another presynaptic molecule, the microtubule-associated protein Tau1 (Dotti et al. 1987). We found a striking reduction in the level of Tau1 in G-Phos dulls relative to G-Phos brights as shown in the CA3 SL subfield (Fig. $7 \mathrm{~B}, \mathrm{C})$. Indeed, there was a near absence of Tau1 staining in this subfield in the G-Phos dulls compared with both the GPhos brights and the wild-type mice (Fig. 7A-C). Pixel intensity measurements (Fig. 7D2) of the Tau1 staining in the CA3 SL revealed an $80 \%$ reduction in the relative Tau 1 staining intensity in the dull group compared with wild type $\left(F_{(2,9)}=11.89\right.$, $P<0.01)$, with the dull group showing less Tau1 immunofluorescence than the other two groups (LSD post-hoc tests, $P<0.01$ for both comparisons). Pixel intensity measurements (Fig. 7D1) of the GAP-43 staining in the dorsal tip of the SL revealed a $54 \%$ increase in the fluorescent signal (i.e., pixel intensity) in the GPhos dulls $(\mathrm{n}=5)$ compared with the G-Phos brights $(\mathrm{n}=4)$ $(P<0.05, t$-test $)$.

\section{Discussion}

The behavioral, in situ hybridization, and immunohistochemical results of the present study all converge to indicate that the level of GAP-43 expression regulates spatial memory. Specifically, overexpression of the phosphorylatable form of transgenic GAP43 protein can, when the task is difficult enough, enhance memory, while doubling this level of transgenic protein impairs memory. The present findings are thus consistent with prior evidence that protein levels in general (Fonseca et al. 2006) and levels of GAP-43 protein in particular (e.g., Benowitz and Routtenberg 1997; Perrone Bizzozero and Tanner 2006) play a critical role in regulating memory processes. Moreover, others have shown that elevations of GAP-43 protein immunolabeling in the anterior cingulate have been linked to remote memory formation (Maviel et al. 2004), and training on a water maze task elevates GAP-43 protein and mRNA expression in the hippocampus compared with swim controls (Pascale et al. 2004). GAP-43 heterozygote knockout mice with a 50\% reduction in endogenous GAP-43 show impaired retention for a contextual fear-conditioning task (Rekart et al. 2005). These data indicate that GAP-43 protein levels prior to behavioral testing can finely calibrate behavioral memory performance, while such performance can then, in turn, 

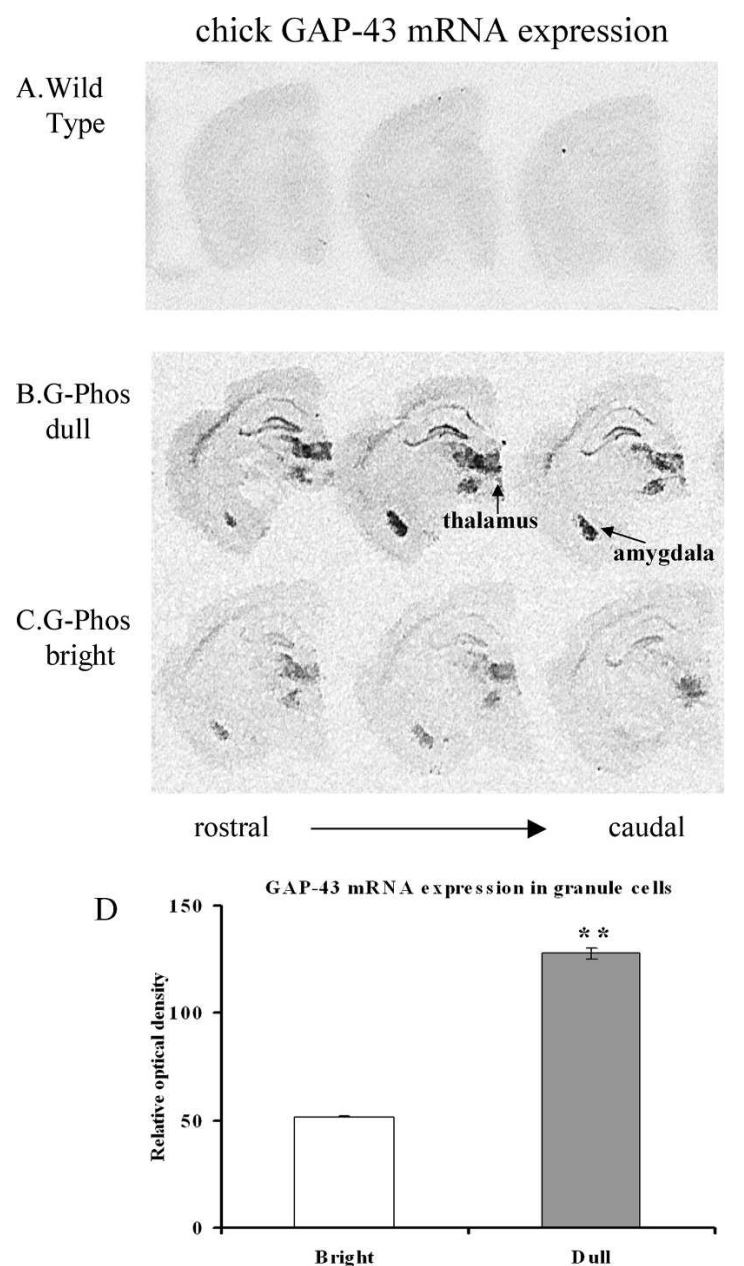

Figure 5. Analysis of the transgenic mRNA levels revealed higher expression in the G-Phos dull than the G-Phos bright mice. Transgene mRNA localization in wild-type mice $(A)$, the G-Phos dull mice $(B)$, and the G-Phos bright mice (C). Transgene GAP-43 mRNA signals in the wildtype mice were, as expected, at background levels, indicating that the oligonucleotide probe selectively hybridized to the transgenic chicken mRNA and not the endogenous mRNA of the mouse. Of particular interest to the spatial memory alterations found in the G-Phos mice, GAP-43 transgene mRNA occurred at moderate (bright) or higher (dull) levels in the pyramidal and granule cells of the hippocampus. $(D)$ Quantification of granule cell relative optical density $\left({ }^{\star * P}<0.01\right.$ dull vs. bright).

regulate levels of this very same protein. Thus, the level of this presynaptic protein both regulates memory formation and is regulated by it.

In a previous report, both wild-type and G-Phos mice acquired the standard radial arm maze at similar rates. However, when the task was more challenging, G-Phos mice showed superior mnemonic ability compared with wild-type mice (Routtenberg et al. 2000). In the present report, we also found memory enhancement relative to wild-type mice in the G-Phos bright mice when the task demands were increased in the water maze. When the hidden platform was moved to a new location each day, the G-Phos bright group showed more rapid learning of the task demands by the third day compared with the wild-type group. Indeed, hippocampal system damage in rats has a significant impairing effect on the flexible use of information as might occur on our nonmatching-to-place task (Eichenbaum et al. 1990). The learning of the new platform location requires the flexible use of spatial associations, i.e., the unlearning of one association and the substitution of another possibly competing response, for which the G-Phos bright mice showed superior performance.

Given the exclusive presynaptic localization of GAP-43 (as reviewed earlier), the altered mnemonic function in both the G-Phos bright and dull groups highlights the role of the presynaptic compartment in the information storage process (cf., Routtenberg 1985, 1990; Powell 2006). Neurotransmitter release and terminal remodeling are two hypothesized presynaptic processes that would likely be altered by overexpression of phosphorylatable GAP-43. Concerning transmitter function, phosphorylation of GAP-43 has been correlated with enhanced release (De Graan et al. 1990b; Dekker et al. 1990; Iannazzo 2001); overexpressing phosphorylatable GAP-43 in the presynaptic terminal is likely to alter this cellular function. Reductions in $\mathrm{Ca}^{++}$-evoked neurotransmitter release have been observed after levels of GAP-43 were reduced using antibodies (Hens et al. 1995, 1998) or antisense oligonucleotides (Ivins et al. 1993). Elevated GAP-43 transgene expression in hippocampal granule cells and protein in the mossy fiber terminal fields could thus enhance signal propagation through the hippocampal network, ultimately leading to enhanced memory function in these animals.

A second mechanism for enhancement including remodeling of presynaptic neurons after learning would presumably facilitate communication among relevant neural circuits (Holahan et al. 2006). Posttranslational modifications of GAP-43 may lead to axonal elongation (for reviews, see Dent and Meiri 1992; Caroni 1997, 2001), as motile growth cones contain lower levels of phosphorylated GAP-43 than stationary growth cones (Dent and Meiri 1992). Phosphorylated GAP-43 binds to actin and inhibits the polymerization-depolymerization cycle, ultimately stabilizing actin filaments and, therefore, axonal architectures (He et al. 1997). These processes may be expected to participate in GAP-43-mediated presynaptic growth during learning in the adult and during development of the hippocampal mossy fibers both in rats (Meberg and Routtenberg 1991) and in mice (Cantallops and Routtenberg 1999).

These mechanisms for memory enhancement are likely disrupted in the G-Phos dull mice, which, in striking contrast to the G-Phos bright animals, possess a memory dysfunction with twice the transgenic GAP-43 levels. The phenotypic pattern of GAP-43 expression observed here is similar to the pattern of results reported by Fischer et al. (2005) who studied inducible transgenic mice that up-regulate the truncated p25 protein, which causes hyperactivation of Cdk5 (Cruz et al. 2003). They showed that transient p25 overexpression enhanced long-term potentiation (LTP) and facilitated hippocampal-dependent memories while prolonged p25 production, increasing levels of overexpression beyond those seen in the transient animals, impaired performance on hippocampal-dependent tasks and was accompanied by synaptic and neuronal loss and impaired LTP (Fischer et al. 2005). These data suggest, in combination with the present findings concerning G-Phos transgenic mice, that while moderate overexpression of plasticity-related proteins can enhance memory, excessive levels of overexpression may culminate in memory dysfunction.

The data presented here and those reported by Fischer et al. as described above may be related to the "burden of plasticity" model of Alzheimer's disease pathophysiology (Mesulam 1999; 2000). This model suggests that risk factors associated with Alzheimer's disease set up downstream physiological barriers to plasticity occurring at synaptic sites. These barriers trigger reactive, possibly compensatory, intensification of plasticity-related neuronal activity upstream in the soma. Thus, it is noted, "over many years, such compensatory processes would lead to chronically high and eventually unsustainable levels of plasticity- 
A1 Day 3 Latencies

A2

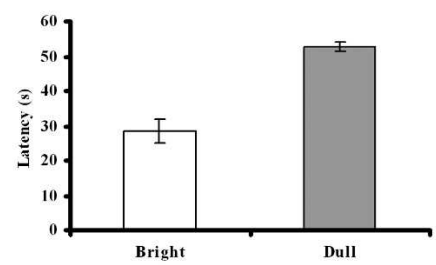

B

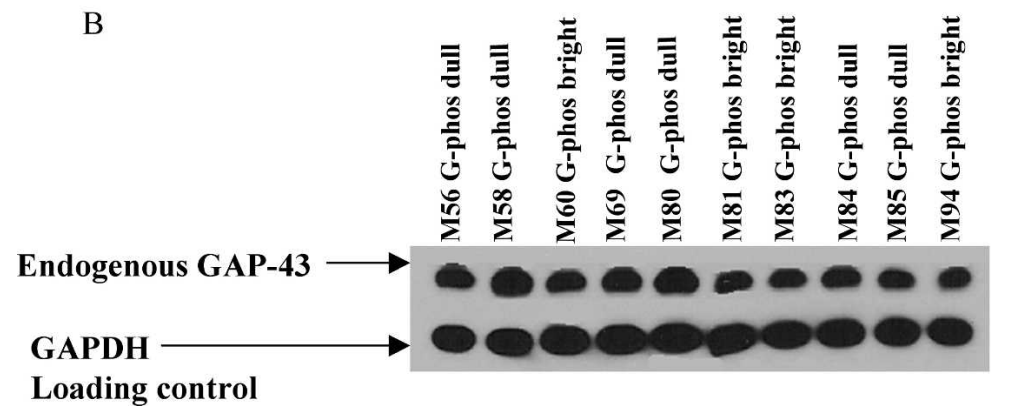

Figure 6. (A1) A separate group of G-Phos transgenic mice $(n=10)$ was trained on the hidden platform water maze task and was divided into bright $(n=4)$ and dull $(n=6)$ subgroups based on Day 3 latencies. (A2) Western blot quantification of endogenous GAP-43 protein levels in the hippocampus revealed no difference between subgroup classifications. (B) Blots of endogenous GAP-43 protein levels in individual G-Phos transgenic mice and blots from the GAPDH loading control. Quantification of endogenous GAP-43 protein levels as shown in A2 was relative to the loading control.

related cellular activity" (Mesulam 2000, p. 525). With high levels of overexpression of phosphorylatable GAP-43, a plasticityassociated protein, occurring in key memory-associated neuronal compartments (e.g., pyramidal cells of the hippocampus), a chronically high level of upstream neuronal activity has essentially been reproduced in the G-Phos dull group. It is in these animals that selective, spatial memory dysfunction occurred. This suggests the possibility that in Alzheimer's pathology, GAP43 up-regulation occurs as a reactive process, but continued, sustained up-regulation ultimately leads to dysfunctional memory circuits.

In post-mortem tissue from Alzheimer's patients, Rekart et al. (2004) reported an elevation in GAP-43 protein staining in the stratum lacunosum moleculare subfield of the hippocampus, which was positively correlated with the severity of disease pathology. Furthermore, in combination with nerve injury, GAP-43 overexpression results in motoneuron death (Harding et al. 1999). These data support the proposal that GAP-43 upregulation initially may serve as a reactive mechanism to injury that may ultimately result in neuronal loss and memory dysfunction.

Inducible transgenic mouse lines chronically overexpressing p25 in the postnatal forebrain exhibited neuronal loss in the cortex and hippocampus as well as forebrain atrophy (Cruz et al. 2003). In relation to Alzheimer's pathology, these mice also presented evidence of hyperphosphorylated tau along with neurofibrillary pathology that developed progressively (Cruz et al. 2003). In our G-Phos dull mice, we observed a decrement in Tau1 staining. We suggest the possibility that the reduction in Tau1 staining occurred as a consequence of its increased phosphorylation because binding of our antibody to the Tau1 protein is ablated by phosphorylation at its Ser199/202 residues. Thus, it may be the case that in the hyperphosphorylated state of Tau in Alzheimer's disease, the Tau1 site is phosphorylated and precludes binding of the antibody. While GAP-43 and Tau1 are colocalized to the presynaptic terminal, the nature of their interaction as suggested by the present novel findings remains to be

\section{Genotyping}

The mice were identified as transgenic or wild type through standard PCR using primers that targeted the DNA sequence for chick GAP-43. Genomic DNA was extracted from the tail using the Qiagen DNeasy Tissue Kit. Only genomic DNA with purity levels $>1.8$ was used for genotyping. Each PCR reaction tube contained $100 \mathrm{ng}$ of genomic DNA, $5 \mu \mathrm{L}$ of PCR buffer, $1 \mu \mathrm{L}$ of dNTPs, 1.5 units of Taq polymerase (Promega), 25 pmol of each primer (sequences: 5'-GACACGGGCTCAGAGCAG-3' and 5'-TTCAGGCA TTTTCTTGGTCC-3'; Invitrogen), and was brought up to a volume of $50 \mu \mathrm{L}$ with autoclaved $\mathrm{diH}_{2} \mathrm{O}$. The reaction tubes were placed in a thermal cycler (Techne) and underwent the following cycle: denature for $5 \mathrm{~min}$ at $94^{\circ} \mathrm{C}, 30$ loops of $1 \mathrm{~min}$ at $94^{\circ} \mathrm{C}, 1 \mathrm{~min}$ at $55^{\circ} \mathrm{C}, 1 \mathrm{~min}$ at $72^{\circ} \mathrm{C}$, and a final extension for $5 \mathrm{~min}$ at $72^{\circ} \mathrm{C}$. Ten microliters of PCR product was mixed with $2 \mu \mathrm{L}$ of loading dye and run on a $2 \%$ agarose gel with ethidium bromide.

\section{Water maze apparatus}

The water maze was a black-painted stainless steel container $2 \mathrm{~m}$ in diameter, $60 \mathrm{~cm}$ high, and filled to a depth of $35 \mathrm{~cm}$ with $22^{\circ} \mathrm{C}$ clear water. The test room was $3 \mathrm{~m} \times 4 \mathrm{~m}$ and illuminated by four spotlights aimed at the ceiling. Within the room there were a number of cues on the walls and a desk on which a computer was located. The experimenter sat in front of the computer and was visible from the pool. The door to the room was located opposite the experimenter. A computer program (HVS Image) tracked the movements of the mice. Successive positions were used to determine latency to reach the platform, swimming distance, and dwell time in certain areas of the pool.

\section{Hidden platform water maze task}

Groups of G-Phos mice and their respective wild-type littermates were run in squads $(\mathrm{n}=6-10 \mathrm{mice} / \mathrm{squad})$ over 6 mo with four replications. Mice were trained on the hidden platform task for 5 $\mathrm{d}$ with eight spaced trials per day ( $5 \mathrm{~min}$ between each trial). The platform was submerged $1 \mathrm{~cm}$ below the water surface. On each trial, a mouse was placed at one of the eight cardinal compass points (pseudorandomly selected; not true direction) along the pool perimeter. For all five training days the hidden platform was in the middle of the northwest quadrant. On each trial, mice

\section{Learning \& Memory \\ www.learnmem.org}




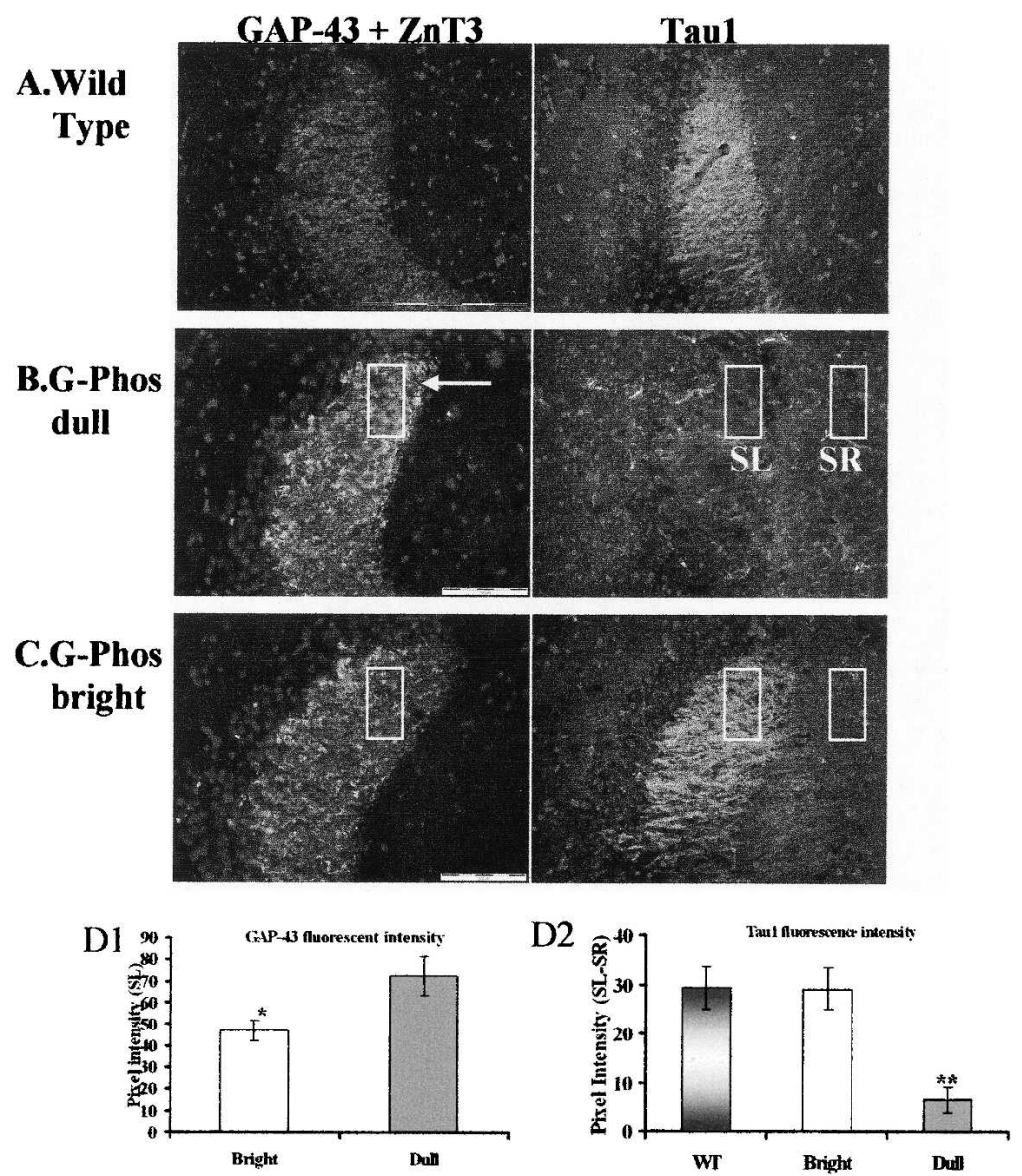

Figure 7. Immunohistofluorescent labeling for the GAP-43 protein (exclusively transgenic in the SL [MFTF]), zinc transporter (ZnT3) protein, and the axon-specific microtubule-associated protein Tau1 in WT mice $(A)$, the G-Phos dull mice $(B)$, and the G-Phos bright mice $(C)$ using DAPI counterstain to indicate cell bodies. Note the elevated levels of GAP-43 staining in the SL of the G-Phos dull mice (pixel intensity measurements in $D 1 ;{ }^{*} P<0.05$ dull vs. bright) and the considerably reduced levels of Tau 1 staining in the SL of the G-Phos dull mouse as compared with the high level of staining in the same region of the G-Phos bright and wild-type mice (quantified in $D 2$, pixel intensity measurements from boxed areas; ${ }^{* *} P<0.01$ Dull vs. WT and Bright). Scale bars in $A$ and $B, 100 \mu \mathrm{m}$.

were allowed to swim freely for up to $60 \mathrm{sec}$. If a mouse did not find the platform in this time, the experimenter guided it there. Each mouse remained on the platform for $20 \mathrm{sec}$ after the end of each trial. At the end of each trial, the mice were dried off with a towel and placed into a warm holding cage in the test room.

\section{Probe test}

Seven days after the last training day, mice were individually brought into the testing room. There was no platform in the pool on this day. The start point for the probe trial was randomly selected from one of the eight start points used during training. The probe trial lasted $60 \mathrm{sec}$. Measures were made for each animal on the amount of time spent searching near the original platform location in the target quadrant and three other randomly selected locations in the other quadrants. The region of interest used was an annulus four times the platform diameter. The 40$\mathrm{cm}$-diameter annulus area $\left(1256 \mathrm{~cm}^{2}\right)$ covers $4.0 \%$ of the total pool area $\left(31,400 \mathrm{~cm}^{2}\right)$.

The circular region of interest neglects time spent along the wall, which likely does not reflect an informed search of a previous platform location (Blokland et al. 2004).

\section{Visible platform water maze task}

Separate groups of mice ( $n=6$ G-Phos, $n=3$ wild type) were first "screened" on a hidden platform task for $5 \mathrm{~d}$ with eight spaced trials per day as described above. The hidden platform was located in the middle of the northwest quadrant of the pool throughout training (as described above).

For the visible platform task, the platform (located in the northeast quadrant) was submerged under water $(1 \mathrm{~cm})$ with a yellow sponge ball attached to it. Mice were given $1 \mathrm{~d}$ of training with five spaced trials. Each mouse was allowed to swim freely for up to $60 \mathrm{sec}$; if a mouse did not find the platform within this time, the experimenter guided it there. The mice remained on the platform for $20 \mathrm{sec}$ after the end of each trial. Each mouse was then taken off the platform and placed into a holding container. The training design was similar to that described for the hidden platform task.

The next day, the platform with the cue was moved to the opposite quadrant and mice were given five trials to locate it in this new position. The start points for the first two trials were located at a point on the perimeter that was equidistant from both the original and new platform locations. Training thereafter occurred as on Day 1.

\section{Hidden platform-Nonmatching to place}

In a separate experiment, different animal subjects ( $\mathrm{n}=10 \mathrm{G}$-Phos and 6 wild type) were first trained on the hidden platform task for $5 \mathrm{~d}$ with eight spaced trials per day as described above. The hidden platform was located in the middle of the northwest quadrant of the pool throughout training.

The nonmatching-to-place task commenced $72 \mathrm{~h}$ after the fifth day of fixed hidden platform training. Mice were trained for $3 \mathrm{~d}$ on this task. On each day, the hidden platform was located in a different quadrant (D1: southeast, D2: northeast, D3: southwest). Trials were similar to those on the first five training days except that the start point for the first trial on each day was located at the pool perimeter halfway between where the platform was located on the previous day and where it was located on the current day's trials.

\section{Histology}

Mice, trained and tested on the initial run and first replication of the hidden platform water maze task, were given an overdose of sodium pentobarbital (Nembutal; $50 \mathrm{mg} / \mathrm{kg}$ ) followed by transcardiac perfusion with $0.9 \%$ saline. Brains were removed and hemisected. The right hemisphere was placed into a $4 \%$ paraformaldehyde/0.1 M phosphate buffered saline solution and stored overnight at $4^{\circ} \mathrm{C}$. The following day the hemispheres were submerged in a $30 \%$ sucrose $/ 0.1 \mathrm{M}$ phosphate buffer solution.

\section{Immunohistochemistry}

Hemispheres were sectioned on a cryostat at $20 \mu \mathrm{m}$ and collected in $0.1 \%$ sodium azide/0.1 $\mathrm{M}$ phosphate buffer. Sections were washed for $15 \mathrm{~min}$ in Tris buffered saline (TBS) and blocked in 1\% normal goat serum for $1 \mathrm{~h}$ at room temperature. Incubation in primary antibodies (GAP-43 1:1000, Sigma; zinc transporter 1:250, gift from R. Palmiter [see Wenzel et al. 1997]); Tau1 antibody 1:10,000, gift from L. Binder [see Dotti et al. 1987]) occurred overnight at $4^{\circ} \mathrm{C}$. The following day, tissue was washed in TBS 
followed by a 2-h incubation in the secondary antibodies (1:500 goat anti-mouse 488 and 1:500 goat anti-rabbit 594, both from Molecular Probes). Tissue was given a final rinse in Tris buffer ( $\mathrm{pH}$ 7.6), mounted on glass slides, and coverslipped using a DAPI hard set-mounting medium (Vector labs).

Pixel intensity measurements were carried out using Olympus Suite software algorithms. For the GAP-43 staining quantification, the area of interest was the dorsal portion of the stratum lucidum (SL) of the CA3 hippocampal region. We focused on this area, as previous work indicated a number of immature axonal terminals that were GAP-43-positive yet synaptophysin- and zinergic-negative. Our analysis was biased to this region for these reasons. A rectangle was placed over this SL region by an experimenter who was blind to behavioral grouping, and pixel intensity measurements were done using the Olympus software. For Tau1 quantification, we used the same area in the SL but also took measurements in the stratum radiatum (SR) and used a relative pixel intensity measurement (SL:SR) to account for the greater background staining that occurred with the Tau1 antibody.

\section{In situ hybridization}

The in situ hybridization procedure followed that as outlined in Wisden and Morris (2002). Antisense and sense oligonucleotides for in situ hybridization were designed to be complementary to nucleotides 281-325 of the chicken cDNA as reported by Baizer et al. (1990). The sequences were: S: 5'-GATGCCCCCGCATCCGA GTCTGAGGCCGCCGACAAGAAGGACGAA-3' and AS: 5'-TTCG TCCTTCTTGTCGGCGGCCTCAGACTCGGATGCGGGGGCATC3 '. BLASTn searches confirmed the specificity of probes to transgenic $G A P-43$ and that probe sequences were not homologous to any known rodent genes. Desalted 50-nt oligonucleotides were synthesized commercially (Invitrogen) and diluted to a concentration of $3 \mathrm{pmol} / \mu \mathrm{L}$ in diethylpyrocarbonate (DEPC)-treated water. Probes were radioactively labeled using terminal deoxynucleotidyl transferase and ${ }^{35} \mathrm{~S}$-ATP. Before hybridization, sections were mounted onto slides and rinsed in $0.1 \mathrm{M}$ TEA/0.25\% acetic anhydride for $10 \mathrm{~min}$, rinsed in $2 \times$ SSC, dehydrated through an ethanol series $(70 \%, 95 \%, 100 \%)$, and allowed to dry. Radiolabeled probes were diluted to a concentration of 200,000 $\mathrm{cpm} / 100 \mu \mathrm{L}$ in $50 \%$ formamide $/ 4 \times \mathrm{SSC} / 10 \%$ dextran sulfate, and $100 \mu \mathrm{L}$ per slide was applied to the sections and covered with parafilm. Sections were incubated for $16 \mathrm{~h}$ at $42^{\circ} \mathrm{C}$ in a chamber humidified with $4 \times$ SSC and 50\% formamide. After hybridization, coverslips were removed and slides were incubated in $1 \times$ SSC for $10 \mathrm{~min}$ at room temperature and then in $1 \times$ SSC for 30 $\min$ at $55^{\circ} \mathrm{C}$. Sections were then rinsed in $0.1 \times$ SSC and dehydrated through an ethanol series (50\%, 70\%, 95\%) and allowed to dry. Hybridized slides were apposed to Biomax MR film (Kodak) for a minimum of $7 \mathrm{~d}$ at room temperature. Densitometric analyses were carried out using ImageJ software.

\section{Western blotting}

A separate group of G-Phos transgenic mice $(n=10)$ were trained on the hidden platform version of the water maze task. After $3 \mathrm{~d}$ of training, animals were split into bright $(n=4)$ and dull $(n=6)$ based on their latencies to locate the platform. Immediately after training, animals were decapitated, and brains were removed and placed into liquid nitrogen for $10 \mathrm{sec}$. Brains were then stored until dissection at $-75^{\circ} \mathrm{C}$. The hippocampus was removed bilaterally from all brains, and tissue was homogenized in cold $\left(4^{\circ} \mathrm{C}\right)$ buffer containing $20 \mathrm{mM}$ Tris- $\mathrm{HCl}(\mathrm{pH} 7.4), 50 \mathrm{mM} \mathrm{NaF}, 0.32 \mathrm{M}$ sucrose, $2 \mathrm{mM}$ EDTA, $2 \mathrm{mM}$ EGTA, $0.2 \mathrm{mM}$ sodium orthovanadate, $2 \mu \mathrm{g} / \mathrm{mL}$ Leupeptin, $2 \mu \mathrm{g} / \mathrm{mL}$ Aprotonin, and $1 \mathrm{mM}$ PMSF. Protein concentration in the homogenates was determined using a Bradford assay. Samples of $10 \mu \mathrm{g}$ of total protein per lane were separated by sodium dodecyl sulfate-polyacrylamide gel electrophoresis on a $10 \%$ polyacrylamide gradient gel for $2 \mathrm{~h}$ at $172 \mathrm{~V}$. The gels were transferred to nitrocellulose membranes (Amersham). Blots were blocked in 5\% dry fat-free milk blocking solution in T-TBS for $30 \mathrm{~min}$ prior to application of the primary antibody (mouse monoclonal anti-GAP-43, Chemicon, 1:4000 to detect endogenous protein only) and incubated overnight at $4^{\circ} \mathrm{C}$. The membrane was washed in TBS for $15 \mathrm{~min}$, then twice in T-TBS for $5 \mathrm{~min}$ and incubated for $1 \mathrm{~h}$ with secondary antibody (1:40,000, Goat anti-mouse IgG, peroxidase-conjugated, Pierce). Immunoreactivity was visualized with Pico West SuperSignal (Pierce).

After probing with anti-GAP-43, the membranes were stripped by incubating in a stripping buffer for $35 \mathrm{~min}$ at $52^{\circ} \mathrm{C}$. Membranes were then reprobed with GAPDH primary antibody (mouse monoclonal anti-GAPDH, Ambion, 1:4000) for loading control purposes. Immunoreactivity was visualized with Pico West SuperSignal (Pierce). The relative amount of protein was quantified in arbitrary units by scanning blots using a computerized software program (ImageJ). The optical densities of GAP43 signals were normalized by GAPDH loading control. The values of GAP-43 bands were divided by the values of GAPDH, which were obtained from the same membrane.

\section{Acknowledgments}

This work was supported by a Postdoctoral Traineeship to M.R.H. (NIA AG20506) and research grant NIH MH65436 to A.R. We thank Dr. L. Binder for generously providing the Tau1 antibody and Dr. R. Palmiter for providing the ZnT3 antibody. We thank Dr. Pico Caroni of the Friedrich Miescher Institute for providing the transgenic mice, Mr. Himanshu Thakur who trained mice on the water maze task, and Drs. M.-Marsel Mesulam and Lester Binder for a critical reading of an earlier version of the manuscript.

\section{References}

Aigner, L., Arber, S., Kapfhammer, J.P., Laux, T., Schneider, C., Botteri, F., Brenner, H.R., and Caroni, P. 1995. Overexpression of the neural growth-associated protein GAP-43 induces nerve sprouting in the adult nervous system of transgenic mice. Cell 83: 269-278.

Alexander, K.A., Wakim, B.T., Doyle, G.S., Walsh, K.A., and Storm, D.R. 1988. Identification and characterization of the calmodulin-binding domain of neuromodulin, a neurospecific calmodulin-binding protein. J. Biol. Chem. 263: 7544-7549.

Baizer, L., Alkan, S., Stocker, K., and Ciment, G. 1990. Chicken growth-associated protein (GAP)-43: Primary structure and regulated expression of mRNA during embryogenesis. Brain Res. Mol. Brain Res. 7: $61-68$.

Basi, G.S., Jacobson, R.D., Virag, I., Schilling, J., and Skene, J.H. 1987. Primary structure and transcriptional regulation of GAP-43, a protein associated with nerve growth. Cell 49: 785-791.

Benowitz, L.I. and Routtenberg, A. 1987. A membrane phosphoprotein associated with neural development, axonal regeneration, phospholipid metabolism, and synaptic plasticity. Trends Neurosci. 10: $527-532$.

Benowitz, L.I. and Routtenberg, A. 1997. GAP-43: An intrinsic determinant of neuronal development and plasticity. Trends Neurosci. 20: 84-91.

Blokland, A., Geraerts, E., and Been, M. 2004. A detailed analysis of rats' spatial memory in a probe trial of a Morris task. Behav. Brain Res. 154: $71-75$.

Cammarota, M., Paratcha, G., Levi de Stein, M., Bernabeu, R., Izquierdo, I., and Medina, J.H. 1997. B-50/ GAP-43 phosphorylation and PKC activity are increased in rat hippocampal synaptosomal membranes after an inhibitory avoidance training. Neurochem. Res. 22: 499-505.

Cantallops, I. and Routtenberg, A. 1999. Activity-dependent regulation of axonal growth: Posttranscriptional control of the GAP-43 gene by the NMDA receptor in developing hippocampus. J. Neurobiol. 41: $208-220$.

Caroni, P. 1997. Intrinsic neuronal determinants that promote axonal sprouting and elongation. Bioessays 19: 767-775.

Caroni, P. 2001. Actin cytoskeleton regulation through modulation of PI $(4,5)$ P2 rafts. EMBO J. 20: 4332-4336.

Chan, S.Y., Murakami, K., and Routtenberg, A. 1986. Phosphoprotein F1: Purification and characterization of a brain kinase $C$ substrate related to plasticity. J. Neurosci. 6: 3618-3627.

Cruz, J.C., Tseng, H.C., Goldman, J.A., Shih, H., and Tsai, L.H. 2003. Aberrant Cdk5 activation by p25 triggers pathological events leading to neurodegeneration and neurofibrillary tangles. Neuron 40: $471-483$.

De Graan, P.N., Oestreicher, A.B., De Wit, M., Kroef, M., Schrama, L.H., and Gispen, W.H. 1990a. Evidence for the binding of calmodulin to endogenous B-50 (GAP-43) in native synaptosomal plasma 
membranes. J. Neurochem. 55: 2139-2141.

De Graan, P.N., Schrama, L.H., Heemskerk, F.M., Dekker, L.V., and Gispen, W.H. 1990b. The role of protein kinase C substrate B-50 (GAP-43) in neurotransmitter release and long-term potentiation. Adv. Exp. Med. Biol. 268: 347-358.

Dekker, L.V., De Graan, P.N., De Wit, M., Hens, J.J., and Gispen, W.H. 1990. Depolarization-induced phosphorylation of the protein kinase C substrate B-50 (GAP-43) in rat cortical synaptosomes. J. Neurochem. 54: $1645-1652$.

Dent, E.W. and Meiri, K.F. 1992. GAP-43 phosphorylation is dynamically regulated in individual growth cones. J. Neurobiol. 23: 1037-1053.

Dotti, C.G., Banker, G.A., and Binder, L.I. 1987. The expression and distribution of the microtubule-associated proteins tau and microtubule-associated protein 2 in hippocampal neurons in the rat in situ and in cell culture. Neuroscience 23: 121-130.

Ehrlich, Y.H., Rabjohns, R.R., and Routtenberg, A. 1977. Experiential input alters the phosphorylation of specific proteins in brain membranes. Pharmacol. Biochem. Behav. 6: 169-174.

Eichenbaum, H., Stewart, C., and Morris, R.G.M. 1990. Hippocampal representation in place learning. J. Neurosci. 10: 3531-3542.

Fischer, A., Sananbenesi, F., Pang, P.T., Lu, B., and Tsai, L.H. 2005. Opposing roles of transient and prolonged expression of p25 in synaptic plasticity and hippocampus-dependent memory. Neuron 48: $825-838$.

Fonseca, R., Vabulas, R.M., Hartl, F.U., Bonhoeffer, T., and Nagerl, U.V. 2006. A balance of protein synthesis and proteasome-dependent degradation determines the maintenance of LTP. Neuron 52: 239-245.

Gianotti, C., Nunzi, M.G., Gispen, W.H., and Corradetti, R. 1992. Phosphorylation of the presynaptic protein B-50 (GAP-43) is increased during electrically induced long-term potentiation. Neuron 8: 843-848.

Harding, D.I., Greensmith, L., Mason, M., Anderson, P.N., and Vrbova, G. 1999. Overexpression of GAP-43 induces prolonged sprouting and causes death of adult motoneurons. Eur. J. Neurosci. 11: 2237-2242.

He, Q., Dent, E.W., and Meiri, K.F. 1997. Modulation of actin filament behavior by GAP-43 (neuromodulin) is dependent on the phosphorylation status of serine 41 , the protein kinase $\mathrm{C}$ site. $J$. Neurosci. 17: 3515-3524.

Hens, J.J., De Wit, M., Boomsma, F., Mercken, M., Oestreicher, A.B. Gispen, W.H., and De Graan, P.N. 1995. N-terminal-specific anti-B-50 (GAP-43) antibodies inhibit $\mathrm{Ca}^{2+}$-induced noradrenaline release, B-50 phosphorylation and dephosphorylation, and calmodulin binding. J. Neurochem. 64: 1127-1136.

Hens, J.J., Ghijsen, W.E., Weller, U., Spierenburg, H.A., Boomsma, F. Oestreicher, A.B., Lopes da Silva, F.H., and De Graan, P.N. 1998. Anti-B-50 (GAP-43) antibodies decrease exocytosis of glutamate in permeated synaptosomes. Eur. J. Pharmacol. 363: 229-240.

Holahan, M.R., Rekart, J.L., Sandoval, J., and Routtenberg, A. 2006. Spatial learning induces presynaptic structural remodeling in the hippocampal mossy fiber system of two rat strains. Hippocampus 16: $560-570$.

Iannazzo, L. 2001. Involvement of B-50 (GAP-43) phosphorylation in the modulation of transmitter release by protein kinase C. Clin. Exp. Pharmacol. Physiol. 28: 901-904.

Ivins, K.J., Neve, K.A., Feller, D.J., Fidel, S.A., and Neve, R.L. 1993. Antisense GAP-43 inhibits the evoked release of dopamine from PC12 cells. J. Neurochem. 60: 626-633.

Liu, Y.C. and Storm, D.R. 1989. Dephosphorylation of neuromodulin by calcineurin. J. Biol. Chem. 264: 12800-12804.

Lovinger, D.M. and Routtenberg, A. 1988. Synapse-specific protein kinase $\mathrm{C}$ activation enhances maintenance of long-term potentiation in rat hippocampus. J. Physiol. 400: 321-333.

Lovinger, D.M., Akers, R.F., Nelson, R.B., Barnes, C.A., McNaughton, B.L., and Routtenberg, A. 1985. A selective increase in phosporylation of protein $\mathrm{F} 1$, a protein kinase $\mathrm{C}$ substrate, directly related to three day growth of long term synaptic enhancement. Brain Res. 343: 137-143.

Lovinger, D.M., Colley, P.A., Akers, R.F., Nelson, R.B., and Routtenberg, A. 1986. Direct relation of long-term synaptic potentiation to phosphorylation of membrane protein F1, a substrate for membrane protein kinase C. Brain Res. 399: 205-211.

Maviel, T., Durkin, T.P., Menzaghi, F., and Bontempi, B. 2004. Sites of neocortical reorganization critical for remote spatial memory. Science 305: 96-99.
Meberg, P.J. and Routtenberg, A. 1991. Selective expression of protein F1/(GAP-43) mRNA in pyramidal but not granule cells of the hippocampus. Neuroscience 45: 721-733.

Mesulam, M.M. 1999. Neuroplasticity failure in Alzheimer's disease: Bridging the gap between plaques and tangles. Neuron 24: 521-529.

Mesulam, M.M. 2000. A plasticity-based theory of the pathogenesis of Alzheimer's disease. Ann. N. Y. Acad. Sci. 924: 42-52.

Nelson, R.B., Linden, D.J., Hyman, C., Pfenninger, K.H., and Routtenberg, A. 1989. The two major phosphoproteins in growth cones are probably identical to two protein kinase $\mathrm{C}$ substrates correlated with persistence of long-term potentiation. J. Neurosci. 9: 381-389.

Nielander, H.B., Schrama, L.H., van Rozen, A.J., Kasperaitis, M., Oestreicher, A.B., Gispen, W.H., and Schotman, P. 1990. Mutation of serine 41 in the neuron-specific protein B-50 (GAP-43) prohibits phosphorylation by protein kinase C. J. Neurochem. 55: 1442-1445

Pascale, A., Gusev, P.A., Amadio, M., Dottorini, T., Govoni, S., Alkon D.L., and Quattrone, A. 2004. Increase of the RNA-binding protein $\mathrm{HuD}$ and posttranscriptional up-regulation of the GAP-43 gene during spatial memory. Proc. Natl. Acad. Sci. 101: 1217-1222.

Perrone Bizzozero, N. and Tanner, D.C. 2006. GAP-43 in neural development and plasticity. In The handbook of neurochemistry and molecular neurobiology (eds. R. Lim and A. Lajtha), pp. 315-330. Springer, New York.

Powell, C.M. 2006. Gene targeting of presynaptic proteins in synaptic plasticity and memory: Across the great divide. Neurobiol. Learn. Mem. 85: 2-15.

Rekart, J.L., Quinn, B., Mesulam, M.M., and Routtenberg, A. 2004. Subfield-specific increase in brain growth protein in postmortem hippocampus of Alzheimer's patients. Neuroscience 126: 579-584.

Rekart, J.L., Meiri, K., and Routtenberg, A. 2005. Hippocampal-dependent memory is impaired in heterozygous GAP-43 knockout mice. Hippocampus 15: 1-7.

Routtenberg, A. 1985. Protein kinase C activation leading to protein F1 phosphorylation may regulate synaptic plasticity by presynaptic terminal growth. Behav. Neural Biol. 44: 186-200.

Routtenberg, A. 1990. Trans-synaptophobia. In Excitatory amino acids and neuronal plasticity. (ed. Y.B. Ari), pp. 401-403. Plenum, New York.

Routtenberg, A. and Ehrlich, Y.H. 1975. Endogenous phosphorylation of four cerebral cortical membrane proteins: Role of cyclic nucleotides, ATP and divalent cations. Brain Res. 92: 415-430.

Routtenberg, A., Cantallops, I., Zaffuto, S., Serrano, P., and Namgung, U. 2000. Enhanced learning after genetic overexpression of a brain growth protein. Proc. Natl. Acad. Sci. 97: 7657-7662.

Skene, J.H. 1989. Axonal growth-associated proteins. Annu. Rev. Neurosci. 12: $127-156$.

Skene, J.H. and Virag, I. 1989. Posttranslational membrane attachment and dynamic fatty acylation of a neuronal growth cone protein, GAP-43. J. Cell Biol. 108: 613-624.

Strittmatter, S.M., Fankhauser, C., Huang, P.L., Mashimo, H., and Fishman, M.C. 1995. Neuronal pathfinding is abnormal in mice lacking the neuronal growth cone protein GAP-43. Cell 80: 445-452.

Tryon, R.C. 1940. Genetic differences in maze learning. Yearbk. Natl. Soc. Stud. Educ. 39: 36-37.

Wenzel, H.J., Cole, T.B., Born, D.E., Schwartzkroin, P.A., and Palmiter, R.D. 1997. Ultrastructural localization of zinc transporter-3 (ZnT-3) to synaptic vesicle membranes within mossy fiber boutons in the hippocampus of mouse and monkey. Proc. Natl. Acad. Sci. 94: $12676-12681$.

Wisden, W. and Morris, B.J. 2002. In situ hybridization with oligonucleotide probes. Int. Rev. Neurobiol. 47: 3-59.

Young, E.A., Owen, E.A., Meiri, K.F., and Wehner, J.M. 2000. Alterations in hippocampal GAP-43 phosphorylation and protein level following contextual fear conditioning. Brain Res. 860: 95-103.

Young, E., Cesna, T., Meiri, K.F., and Perrone-Bizzozero, N. 2002. Changes in protein kinase $\mathrm{C}$ (PKC) activity, isoenzyme translocation, and GAP-43 phosphorylation in the rat hippocampal formation after a single-trial contextual fear conditioning paradigm. Hippocampus 12: $457-464$.

Zuber, M.X., Strittmatter, S.M., and Fishman, M.C. 1989. A membrane-targeting signal in the amino acid terminus of the neuronal protein GAP-43. Nature 341: 345-348.

Received March 19, 2007; accepted in revised form April 3, 2007. 


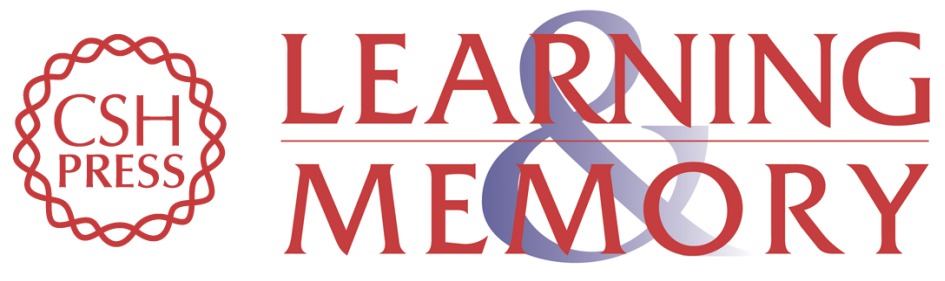

\section{GAP-43 gene expression regulates information storage}

Matthew R. Holahan, Kyle S. Honegger, Nino Tabatadze, et al.

Learn. Mem. 2007, 14:

Access the most recent version at doi:10.1101//m.581907

References This article cites 56 articles, 12 of which can be accessed free at: http://learnmem.cshlp.org/content/14/6/407.full.html\#ref-list-1

License

Email Alerting Receive free email alerts when new articles cite this article - sign up in the box at the Service top right corner of the article or click here. 